\title{
Altimetry Quality of SRTM and ASTER GDEM Products for Areas with Different Reliefs
}

\author{
Vivian da Silva Celestino Reginato \\ Department of Civil Engineering, Federal University of Santa Catarina (UFSC), Florianópolis, Brazil \\ Email: vivian.celestino@ufsc.br
}

How to cite this paper: da Silva Celestino Reginato, V. (2019) Altimetry Quality of SRTM and ASTER GDEM Products for Areas with Different Reliefs. Journal of Geographic Information System, 11, 683-714. https://doi.org/10.4236/jgis.2019.116042

Received: October 31, 2019

Accepted: December 10, 2019

Published: December 13, 2019

Copyright $\odot 2019$ by author(s) and Scientific Research Publishing Inc. This work is licensed under the Creative Commons Attribution International License (CC BY 4.0).

http://creativecommons.org/licenses/by/4.0/

\begin{abstract}
Hydroelectric power plants cause impacts that are usually estimated by an indicator, the hydroelectric power generation per hectare of flooded area. And, although entrepreneurs use quality-declared cartographic bases to comply with the standards, at the project stages of a hydroelectric plant it is not a priori determined whether the altimetry tolerance of such bases is sufficient to ensure that the impacts will not increase, which in the project consolidation becomes a huge problem. This work aims to define the altimetry quality of SRTM Digital Elevation Models (DEM) and ASTER GDEM and whether they are a priori sufficient to simulate the flood level of hydroelectric power plants in different reliefs. To accomplish this objective, a morphological method of assessment of the DEM quality was developed, through Geographic Information Systems (GIS), so that the altimetry information generated by the models and field surveys, when compared, would show their actual differences also in relation to their areas. To this end, two study areas were used: one with a slightly undulated relief and the other with undulated relief. To validate the models, quality assessments were carried out: based on points, according to the Brazilian Map Accuracy Standard (MAS) and STANAG 2215; and based on surfaces, according to Article 500 of the Brazilian Civil Code and the morphological method. At the end, practical applications relating to the M\&P indicator and hydroelectric power plants projects were also carried out. The results presented demonstrate that the quality of an SRTM DEM when used in undulating or gently undulating reliefs can be used up to 1:80,000 scale. Already for DEM ASTER under the same conditions, it is possible to use on the scale 1:100,000. In DEM SRTM and DEM ASTER, after removing the systematic error $(-7.3 \mathrm{~m})$ and $(-6.2$ $\mathrm{m})$, respectively, the quality between $65 \%$ and $79 \%$ is verified for DEM SRTM and 53\%, and 68\% for DEM ASTER for common areas in flood level simulation.
\end{abstract}




\section{Keywords}

Altimetry Quality, Geographic Information Systems (GIS), Remote Sensing, Digital Elevation Model (DEM), Morphology

\section{Introduction}

Water resources are physical bodies primarily composed of lakes, lagoons, rivers, streams, among others. Such water bodies have dynamic characteristics due to the action of Earth' physical forces, which attract waters to low-altitude regions to finally encounter the sea or a barrier. When the water flow encounters a barrier and crosses a power plant, energy is generated, called hydroelectric power [1].

Hydroelectric power plants (HPP), in general, use reservoirs to equalize the rate of water flows that drive turbines. Such dams are preferably built in narrow, deep canyons and in relatively small flooded areas. As there are few places that meet these conditions, concrete and rock fill (stones and earth) dams are also built, having low height and long length, requiring flooding of large surface extensions [2], causing environmental impacts.

The impact of an HPP can usually be estimated by an indicator, the hydroelectric power output in kilo Watt $(\mathrm{kW})$ per hectare (ha) of flooded area, herein called M\&P indicator. The higher this number, the smaller will be any possible impact on the environment [3].

Flood is a key indicator of the environmental impact caused by an HPP, but not the only one. It is necessary to build new plants-with minimal socioenvironmental impact-to produce energy sufficient to promote economic growth and jobs generation [4].

Despite the use of quality-declared cartographic bases to meet ANEEL and Eletrobras norms and standards, at the study phase of the project, the altimetry tolerance of such bases should be checked a priori to make sure that socioenvironmental impacts will not increase when projects are consolidated [5].

Due to this problem, the objective of this study was to develop a method to assess DEM altimetry quality, taking into consideration the terrain morphology/relief, so that the altimetry data generated by the DEM and field surveys, when compared, would show their actual differences in relation to the flooded areas.

For this purpose, the surroundings of two Hydroelectric Power Plants (HPP) owned by the Eletrosul company were used as study areas.

In short, the research aimed to define that the main information that must be drawn from a cartographic base when the first projects of an HPP are outlined is the altimetry data in the form of a line that simulates the flood (future HPP lake). This line necessarily arises from interpolations or extrapolations based on altitude points, contour lines, DEM or others already existing, and must be uti- 
lized following the quality standards linked to the relief of the area.

\section{Theoretical Framework}

The concepts described below serve as the basis for the understanding of the research. Several researches have been developed by scientific community to evaluate the altimetry accuracy of the free distribution DEM, as well as for identification of the possible factors that can influence this altimetry data quality. In the search of the [6] was presented results above expectations, in the search of the [7] was evaluated SRTM for a smooth relief area reporting the smallest errors (Root Mean Square Error $($ RMSE) $=9.85 \mathrm{~m}$ ) and, also, for an area with mountainous relief, where the biggest errors were identified (RMSE $=22.96$ ). In the search of the [8], when evaluating an DEM SRTM, verified a quality compatible with the scale 1:250,000.

About the DEM ASTER, some evaluations regarding the PEC performed by [9] showed that the average of the altimetric differences between the DEM coordinates and the reference coordinates was smaller than the USGS value of $20 \mathrm{~m}$ and in the [10] was evaluated ASTER GDEM data for areas with different types of relief and soil cover, concluding that the typical urban areas presented the highest altimetry errors (RMSE $21.21 \mathrm{~m}$ ). In the paper of the [11] was found RMSE of $12.12 \mathrm{~m}$ for DEM ASTER and in the [12] was found PEC, Class B, associated to mapping scale 1:100.000 for DEM ASTER.

The consistency of the altimetry errors observed in evaluated DEM for any application is directly related to the objective of the DEM use associated to the mapping scale applied [13]. DEM SRTM and DEM ASTER were evaluated were evaluated by the authors that realized that the values of RMSE increased with increasing slope of the land. In the paper of the [6] and [14] was indicate a Class A Cartographic Accuracy Standard (PEC), associated to 1:100,000 mapping scale, for both DEM SRTM and DEM ASTER, that converged with results by [15].

This research aims to meet a demand related to the application of DEM SRTM and DEM ASTER in hydroelectric plants, because very little on the subject is found in the available literature. In the search of the [16] was verified that DEM SRTM was not adequate to identify places with potential for hydroelectric power generation for the studied region. The main factor that stands out and becomes relevant in this research is the fact that quality assessment was performed through topographic surveys via geometric accuracy leveling, being $5 \mathrm{~cm}$ the quality of both planimetric and altimetric reference bases.

\subsection{Studies and Projects Stages for Implementation of a Hydroelectric Enterprise}

According to manuals [17] [18] and [19], in short, the studies and projects stages for implementation of a hydroelectric project are divided into various phases, as follows: 
- Estimation of Hydroelectricity Production: preliminary analysis of the watershed characteristics based on available data and conducted in the office.

- Hydroelectric Inventory: conception and analysis of various alternatives for division of fall into watersheds. It comprises the Study Planning; Preliminary Studies, Final Studies phases, and the Integrated Environmental Assessment of the Selected Alternative.

- Feasibility: technical, energy, economic and socioenvironmental feasibility analysis. They consist of field surveys, reservoir dimensioning, area of influence and infrastructure works.

- Basic Project: definition of the technical characteristics of the project, technical specifications for civil works, equipment and socioenvironmental programs.

- Executive Project: it consists of the preparation of detailing drawings of civil works and equipment, as necessary for the execution of the works, erection and assembly (reservoir implementation.

\subsection{Geometrical Elements of Relief}

The geometrical elements of a relief, according to the [20], can be classified geometrically according to its inclinations and slopes. Inclination expresses the mean angle formed by the intersection of the vertical slope line and the horizontal axis usually measured from its base. The slope represents the angle inclination expressed in percent ratio between the vertical slope line and the length of the hillslope horizontal line, according to the following equations:

$$
\begin{gathered}
I=\operatorname{ARCTAN}(H / L) \\
S=H / L \times 100
\end{gathered}
$$

where:

- $I$ is inclination.

- $S$ is slope.

- $H$ is the vertical slope line.

- $L$ is the length of the horizontal line.

Table 1 shows the ratio values of inclination and slope.

Reference [21] also defined classifications of relief slopes, but as a function of the terrain geomorphology, as follows:

Table 1. Inclination to slope ratio [20].

\begin{tabular}{cc}
\hline Inclination (I) & Slope (\%) \\
\hline $45^{\circ}$ & $100 \%$ \\
$\sim 27^{\circ}$ & $50 \%$ \\
$\sim 17^{\circ}$ & $30 \%$ \\
$\sim 11^{\circ}$ & $20 \%$ \\
$\sim 7^{\circ}$ & $12 \%$ \\
$\sim 3^{\circ}$ & $6 \%$
\end{tabular}


- Flat: slopes lower than $3 \%$.

- Mildly undulated: slopes between 3\% and $8 \%$.

- Undulated: slopes between $8 \%$ and $20 \%$.

- Strongly undulated: slopes between $20 \%$ and $45 \%$.

- Mountainous: slopes between $45 \%$ and $75 \%$.

- Steep: slopes higher than $75 \%$.

\subsection{Cartographic Quality}

The product quality must be assessed whenever a document that is being used does not specify its geometrical quality, which is the case of orbital images [22]. The process quality must be assessed throughout the work stages by means of criteria that ensure data accuracy. The final product assessment should be made through the cartography test, by different methods or according to accuracy standards.

In Brazil, the law that deals with the quality of cartographic products is Decree $n^{\circ} 89.817$ of 1984, which establishes Regulatory Instructions of Technical Standards for National Cartography and presents an assessment of the maps quality regarding the accuracy of the cartographic information, creating the Map Accuracy Standard (MAS) and a classification, as shown in Table 2.

The National Spatial Data Infrastructure and the Geographic Service Board adopted a new quality standard, called Map Accuracy Standard for Digital Cartographic Products (MAS-DCP) [24]. The set of preliminary values for these standards was intitled Accuracy and Precision Standard for Digital Cartographic Products (APS-DCP), with definitions and values analogous to MAS. This standard adopted for altimetry the same values of MAS 1984 and included Class D with values of 1 of equidistance for accuracy and 3/5 of equidistance for Standard Error (SE). Tolerances have also been defined for digital products such as Digital Terrain Models (DTM), DEM, Digital Surface Models (DSM) and Altitude Points (in Brazil they are called pontos cotados [quoted points]).

With respect to international cartographic legislation, there are various documents in force and in progress. The Evaluation of Land Maps, Aeronautical Charts and Digital Topographic Data (STANAG) 2215 is a document that resulted from the standardization of the North Atlantic Treaty Organization (NATO) 2001 [25], and describes the methodology for obtaining planialtimetric data from a sample of 167 points. STANAG considers absolute vertical accuracy as a linear error along $\mathrm{Z}$-axis. The products ratings for the necessary altimetry accuracies are listed in Table 3.

Table 2. MAS 1984 for altimetry [23].

\begin{tabular}{ccc}
\hline Cartography & MAS 1984 & Standard error (SE) \\
\hline Class A & $1 / 2$ equidistance & $1 / 3$ of equidistance \\
Class B & $3 / 5$ equidistance & $2 / 5$ of equidistance \\
Class C & $3 / 4$ equidistance & $1 / 2$ of equidistance
\end{tabular}


Table 3. STANAG 2215 vertical accuracy [25].

\begin{tabular}{ccccc}
\hline Rating & 0 & 1 & 2 & 3 \\
\hline Scale & $1 / 25,000$ & $2.5 \mathrm{~m}$ & $5 \mathrm{~m}$ & $10 \mathrm{~m}$ \\
Scale & $1 / 50,000$ & $5 \mathrm{~m}$ & $10 \mathrm{~m}$ & $20 \mathrm{~m}$ \\
Scale & $1 / 100,000$ & $10 \mathrm{~m}$ & $20 \mathrm{~m}$ & $40 \mathrm{~m}$ \\
Scale & $1 / 200,000$ & $20 \mathrm{~m}$ & $40 \mathrm{~m}$ & $80 \mathrm{~m}$ \\
Scale & $1 / 250,000$ & $25 \mathrm{~m}$ & $50 \mathrm{~m}$ & $100 \mathrm{~m}$ \\
\hline
\end{tabular}

With respect to evaluations not based on points, only Law $\mathrm{N}^{\circ} .10 .406$, of January 10, 2002, of the Brazilian Civil Code, sets forth (translated by the author):

"Art. 500. In the event that, in the sale of a property, the price is determined by the extension measure or if the respective area is determined, and if this does not correspond, in any case, to the dimensions given, the buyer shall have the right to demand the complement of the area, and, if not possible, to claim the termination of the contract or a proportional abatement of the purchase price.

Paragraph 1. The reference to dimensions will be assumed to be simply enunciative when the difference found does not exceed 1/20 of the total area declared, and the buyer shall have the right to prove that, in such circumstances, he would not have closed the deal.

Paragraph 2. In the event that, instead of lack, there is excess, and the vendor proves that he had reasons to ignore the exact measure of the area sold, the buyer, at his/her discretion, shall complete the amount corresponding to the price or return the excess. [26]"

In paragraph 1 , it is specified that the difference must exceed $1 / 20$ of the area in order that the difference in dimensions can be formalized. One twentieth of the area corresponds to $5 \%$ of the area.

The definition of criteria for choosing the number of points for quality assessment may be performed using a statistical method, specifically the statistical function of Pereira [27].

$$
\begin{gathered}
n:=\frac{Z^{2} \cdot \gamma^{2} \cdot N}{(n-1) \cdot(\varepsilon r)^{2}+Z^{2} \cdot \gamma^{2}} \\
\varepsilon r:=\frac{\varepsilon}{\mu} \\
\gamma:=\frac{\sigma}{\mu}
\end{gathered}
$$

where:

$$
\begin{aligned}
& n=\text { control points. } \\
& N=\text { base points (vectors) } . \\
& \mathcal{E}=\text { control point error }(\mathrm{m}) . \\
& \mathcal{E} r=\text { relative control point error. }
\end{aligned}
$$


$\sigma=$ RMSE control point (m).

$\mu=$ average control points (m).

$Z=$ Reliability Level of Normal Distribution Table (90\%).

$\gamma=$ Relation $\sigma$ between $\mu$.

\subsection{Spatial Interpolation and the Topo to Raster Method}

There are various interpolation tools for diverse purposes, but [28] observed that the ANUDEM method is indicated to generate accurate elevation models, since the erosive effect of water alters considerably the relief contours. The method was specifically designed to create a ground surface that best represents natural drainage and best preserves the ridgelines. The current version of ANUDEM used in ArcGIS it the Topo to Raster.

\subsection{Radio Detection and Ranging (RADAR) Space Shuttle Topography Mission (SRTM)}

The Space Shuttle Radar Topography Mission (SRTM) of the National Aeronautics and Space Administration (NASA) was launched in February 11, 2000 in a period of 11 days. SAR radars in $\mathrm{C}$ and $\mathrm{X}$ bands were used to obtain topographic data on more than 80 percent of the Earth's emerged area, between 60 degrees North and 56 degrees South [29].

The DEM derived from SRTM of a great part of the planet are now available with a spatial resolution of $30 \mathrm{~m}$. Data can be obtained on http://www-radar.jpl.nasa.gov/srtm [30].

According to [31] and [32], C-band radar data provided by the SRTM mission, with spatial resolution of $90 \mathrm{~m}$, has an absolute vertical and horizontal accuracy of 16 and $20 \mathrm{~m}$, respectively, with $90 \%$ of confidence.

Diverse works have been developed to assess the quality of the DEM obtained via SRTM, and in some of them the results were higher than the expected ones, e.g., [6].

Others, such as in [8], the DEM was suitable for utilization only on scale 1:250,000 or lower, and in [16], the DEM from SRTM was not adequate to identify places with potential for hydroelectric power generation for the region studied.

\subsection{Advanced Spaceborne Thermal Emission and Reflection Radiometer Global Digital Elevation Model (ASTER GDEM)}

ASTER is a cooperation effort between NASA and the Ministry of International Trade and Industry in Japan (MITI), the Earth Resources Data Analysis Center (ERSDAC) and the United States Geological Survey (USGS) to build a global, free access DEM. Since 2009, the DEM built from stereoscopic pairs of images provided by the ASTER instrument have been available at no cost and without restrictions [33].

To obtain surface elevation data, the sensor operates at the stereoscopic mode with $3 \mathrm{~N}$ (nadir) bands and 3B (backward) bands corresponding to the near infrared range. This product has a 30-m spatial resolution and covers the entire 
globe. It is the most complete land map of Earth, covering 99\% of the its surface. The GDEM covers the terrestrial surface between latitudes of 83 degrees North and 83 degrees South, with images of 1 degree per 1 degree [9].

On the USGS website, it can be found the accuracies of ASTER GDEM, the vertical accuracy of the DEM ASTER GDEM being of $20 \mathrm{~m}$ for $95 \%$ of the points sampled. In the same document, the stated horizontal accuracy of this product is $30 \mathrm{~m}$ (1 pixel) also for $95 \%$ of the sample [34].

The evaluations related to the MAS that reference [9] conducted show that the mean altimetric differences between the images tested and the reference coordinates were lower than the value shown by USGS.

\section{Materials and Methods}

This section presents the characteristics of the study areas, a description of the materials (cartographic products, software and hardware units) used and the method developed in the research.

\subsection{Stydy Areas}

Two Eletrosul-owned HPPs were defined as the study areas. All information relating to the altimeter bases was kindly provided by this company.

The Passo São João HPP (PSJHPP), built in the Ijuí River, between the municipalities of Roque Gonzales, Dezesseis de Novembro, São Luiz Gonzaga, São Pedro do Butiá and Rolador (Northwest of Rio Grande do Sul), is a run-of-theriver power plant with an installed capacity of $77 \mathrm{MW}$ [34]. The plant has a total flooded area of $25.24 \mathrm{~km}^{2}$, perimeter of de $181 \mathrm{~km}$ and reached 518 urban and rural properties during its implementation. It started operations in 2012. The Flood Level (FL) of the plant is $128.25 \mathrm{~m}$. See a panoramic picture of the PSJHPP in Figure 1.

The São Domingos HPP (SDHPP) built in the Verde River, between the municipalities of Ribas do Rio Pardo and Água Clara (Mato Grosso do Sul), is also a run-of-the-river power plant with an installed capacity of $48 \mathrm{MW}$ [35]. The plant has a total flooded area of $18.64 \mathrm{~km}^{2}$, perimeter of de $76.50 \mathrm{~km}$ and covered 25 rural properties during implementation. It started operations in 2013. The FL of the plant is $345 \mathrm{~m}$. See a simulated picture of SDHPP (Figure 2).

\subsection{Materials}

The materials (cartographic products) and equipment units (hardware and software) used are listed below:

- SRTM DEM;

- ASTER GDEM;

- Eletrosul field surveys: geometric leveling lines with 5-centimeters $(\mathrm{cm})$ accuracy in altimetry and $10 \mathrm{~cm}$ in planimetry;

- Global positioning Satellite System (GNSS);

- Software: AutoCAD Map; ArcGIS; DXF2XYZ; and Excel;

- Hardware: Computers and Notebook. 


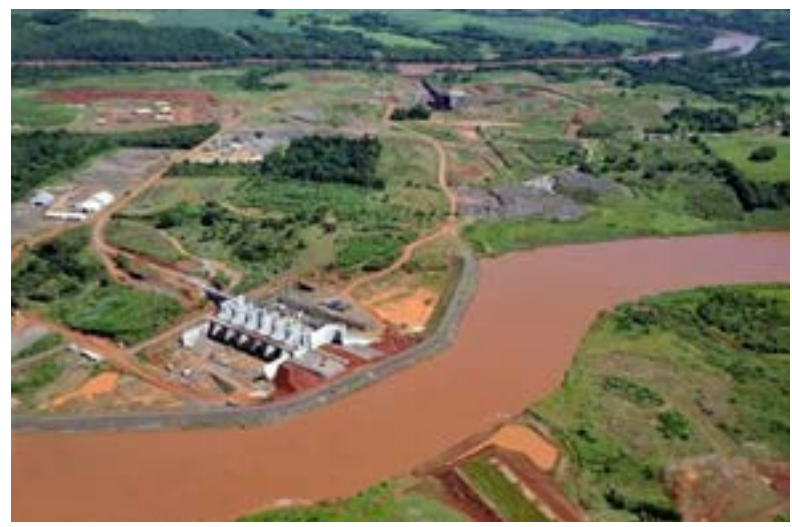

Figure 1. PSJHPP: Panoramic photograph [35].

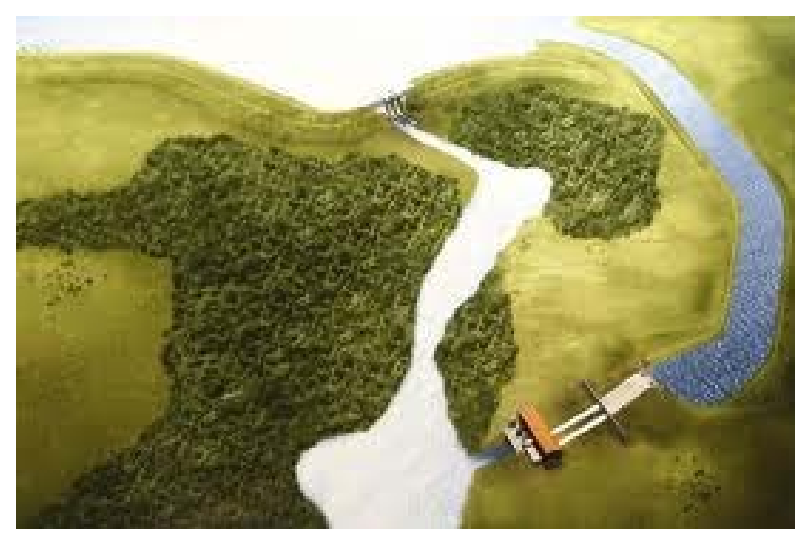

Figure 2. SDHPP: Simulated photograph [36].

\subsection{Method}

In this section, the research phases are described. First, an evaluation of data quality per control point was conducted, using as reference the MAS and the STANAG, and then existing trends were checked by hypothesis testing. Subsequently, the terrains morphology in the study areas was evaluated, and, finally, practical applications were made to the M\&P indicator and the hydroelectric project stages.

\section{1) Quality Assessment per Control Point}

It was carried out by control points only to verify the altimetry quality of the products tested without considering the relief of the studied regions.

First, the products' declared accuracy was checked to ensure, in the evaluation, control points with accuracy three times better than the one declared by the bases tested. As declared accuracies we considered the definitions contained in item 2.3-MAS planialtimetry Class A standard and STANAG 2215 Class A planialtimetry and Class 0 altimetry applied to the products scales.

Field location and respective materialization (physical demarcation with stakes) of the FL were performed for each HPP by geometric accuracy leveling. For the planialtimetric survey of the staked points, GNSS orbital surveying with the relative method of positioning and static mode was performed. 
The plane coordinates derived from reference bases surveys were transformed into coordinates matrices by the DXF2XYZ software, where the number of coordinates of each base was quantified. Each planimetric coordinate from the bases reference received a number in ascending order.

To define the number of control points, the equations 3, 4 and 5 [27] were used to define the number of points to be used as a sample. Approximately 32 (thirty two) control points were indicated for each base. However, as a guarantee, 40 (forty) were used for each study area.

Having considered as homogeneous the errors distribution in all bases tested, a distribution method of control points also homogeneous was adopted. To this end, a simple, unbiased random draw method was utilized, by simple manual draw without replacement, to indicate the 40 vectors (control points) of the reference bases that should be entered into the tested bases.

The 40 reference planimetric coordinates drawn were included into each base to be tested, and manual interpolations were performed using the AutodeskMap software to calculate the new coordinate altitudes. At the points not fitting in between contours of different altitudes, the value of the curve involving the point was defined with no need for interpolation.

To validate the bases tested and verify whether they had the same quality as stated, which was verified a priori, the evaluation method followed the standards defined in item 2.3.1. For this, the tested bases were classified according to the following criteria:

- The tested control points utilized must represent $100 \%$ of the universe of points;

- The coordinates of the control points tested cannot exceed the maximum acceptable error in relation to MAS and the SE identified in the calculation of residuals in number higher than $10 \%$ of total.

- The coordinates of the control points tested cannot exceed the maximum acceptable error in relation to the STANAG identified in the calculation of residuals in number higher than $10 \%$ of total;

- The products that have a number of points with error above the acceptable limit in quantity equal to or below that specified by MAS must be classified into A, B or C cartographic classes;

- The products with a number of points with error above the acceptable limit, in an amount above that specified by MAS, cannot have a defined class;

- The products with a number of points with error above the acceptable limit, in an amount equal to or below that specified by the STANAG 2215 altimetry must be classified into $0,1,2,3$ or 4 standards.

Each study area showed 40 planimetric coordinates with two altitudes (one of reference and one of test) for each product tested. The differences of each one were calculated and then compared with MAS and STANAG 2215.

For the difference values, the means and sample standard deviations were calculated, and hypothesis tests were applied first for the mean and T-Student Distribution and, then, by application of Normal Distribution (with attribution 
of the declared SE of the products as population standard deviation). In the bases where systematic trend was found, extraction of the trend was performed by basic arithmetic (sum or subtraction) through maps algebra, and again the quality standards were applied to the bases and new comparisons were performed.

\section{2) Morphological Evaluation}

At this stage, the altimetry quality of the products was verified, considering the dimensions formed by the surface covered by the simulated curves in relation to the reference curve for each product and study area tested. For this purpose, several GIS tools were used.

First, the study areas had their reliefs classified in relation to inclination/slope. The calculation and respective classification were performed according to the definitions described in section 2.2. by using the formulations of Equations (1) and (2).

From each DEM, the contour lines that simulated the FL of each HPP were extracted. Extraction of the contours was done automatically through the Contour function of the Spatial Analyst tool of the ArcGIS software. For the bases from which systematic trends were removed, the contours were also extracted, and this stage was named "Extraction of re-simulation curves".

Cartographic generalizations were conducted to eliminate islands and also the contours that exceeded the area demarcated by the FL. The limits defined were the dams of each HPP as well as the end of the flooded area upstream each river.

To check for the quality of the products tested, that is, for the homogeneous distribution of the area formed by the simulated/re-simulated curves in relation to the reference curves, the method of evaluation followed the standards defined in 2.3., "Article 500 of the Brazilian Civil Code". The products were then rated according to the following criteria:

- It was considered as given dimension (extension measure usually recorded on the property deed), that one formed by the curves extracted directly from the products tested (DEM) in their respective FL;

- It was considered as determined dimension the extension measured on field by geometric leveling and planialtimetric survey of the Reference Bases;

- The products that exhibited differences between the dimensions formed by the simulated/re-simulated curves and the reference curve of less than one twentieth of the total stated area, i.e., less than $5 \%$, were approved;

- The products that exhibited differences between the dimensions formed by the simulated/re-simulated curves and the reference curve of more than one twentieth of the total stated area, i.e., over 5\%, were disapproved;

- It was defined as an absolute evaluation method the one which considered only the absolute dimension differences (area and perimeter) of the curves generated by the products tested in the measurement, without considering the location/spatialization of the same in relation to the curve of reference, as if the simulated/re-simulated curves had been produced by any expedient 
method, without considering neighboring boundary lines or any kind of linkage or georeferencing;

- It was defined as a relative evaluation method the one which considered, in addition to dimensions (area and perimeter) of the curves generated by the products tested in the measurement, the relative location/spatialization (georeferencing), i.e. the total area that is formed by joining the areas and, in the common area, by the areas intersection, between the simulated/re-simulated curves and the reference ones.

The differences between the simulated/re-simulated areas and the reference ones in the absolute form were calculated using the Autodesk software in the area function. To generate the polygons of the total area and common area of the simulated/re-simulated curves and the reference ones, the geoprocessing tool of the ArcGIS software was used, in the merge and intersect functions, respectively. To this end, the following relationships were used:

$$
\begin{aligned}
& \mathrm{FL} \cap \mathrm{SI}=\mathrm{CA} \\
& \mathrm{FLUSI}=\mathrm{TA}
\end{aligned}
$$

where:

$U=$ set of union of all spatially-related polygons;

$\bigcap=$ intersection set of spatially-related common polygons;

$\mathrm{FL}=$ area formed by the reference curve polygon;

$\mathrm{CA}=$ common area formed by the intersection of polygons of the reference curve and the simulated/re-simulated curve;

SI = simulated area formed by the polygon of the simulated/re-simulated curve;

$\mathrm{TA}=$ total area formed by the union of polygons of the reference curves and the simulated/re-simulated curves.

After that, a morphological evaluation was carried out, which is related to the evaluation of the geometric shape of the polygons formed by the simulated/resimulated curves (contours) and their respective quantitative differences in relation to the polygons formed by the reference curves. To this end, the dimensions formed between the reference curves and the simulated/re-simulated ones, except for the common areas, were calculated by simple logic using the merge, intersect and clip functions of ArcGIS software. The relations of Equations (6) and (7), as well as the following ones, were used:

$$
\begin{aligned}
& \mathrm{FL}-\mathrm{CA}=\mathrm{IA} \\
& \mathrm{TA}-\mathrm{FL}=\mathrm{OA}
\end{aligned}
$$

where:

$\mathrm{IA}=$ inside area formed by the polygons positioned between the reference curve and the simulated/re-simulated curve;

$\mathrm{OA}=$ outside area formed by the polygons positioned between the simulated/re-simulated curve and the reference one. 


\section{3) Applications}

The results from the simulated/re-simulated curves of the products tested enabled a practical application to two situations usually used in engineering, as defined below.

First, the products tested were classified according to the indicator proposed by [3], herein called M\&P indicator, which considered the output, or power generation, of the future HPP and probable flooding area. The values that varied up to more or less than $20 \%$ in relation to the calculated reference value were used as parameters.

The second application consisted of fitting the bases into the following projects stages (the "Executive Project" stage, because it is the consolidated stage, will not be part of the assessment because it requires, for implementation, large topographic scales, thus not fitting, a priori into any product tested):

- Office stages: Estimation of the Hydroelectric Potential and Hydroelectric Inventory;

- Stages that require complementation with field works: Feasibility and Basic Design.

In this work, the optimal curves to be applied in hydroelectric projects were the ones that had larger surfaces in common with those formed by the reference curves, followed by those that, which had no common surfaces exhibited surfaces distribution either inside or outside the reference altitude at a rate of 50\% each, to compensate for losses and gains.

In the case of FL simulation/re-simulation by different bases, the areas formed either outside or inside the graphic environment in relation to the reference FL (the altitude effectively defined on field and its consequent filling), must be analyzed carefully because, depending on what it is considered as the best or worst case, from the entrepreneur's point of view or that affected by damming (the owner of the land to be inundated), it may interfere with the results and analyses.

In large plants, if the areas estimated by simulation/re-simulation in the phases of study are larger than the effective one found in the consolidated phases of the project, it could affect the other phases, such as, for instance, the inventory and feasibility study. In these cases, it could and should be recommended to carry out more studies to obtain higher quality information before considering the project unviable.

On the other hand, if the areas estimated by simulation/re-simulation in the phases of study are smaller than the effective one found in the consolidated phases of the project, it could be a problem because a larger flooded area may result in a greater number of affected properties, with larger areas of suppressed vegetation, among others, which will ultimately cause losses to entrepreneurs and an adverse impact on the affected community.

For a better understanding of the research is being presented the flowchart of the method in Figure 3. 


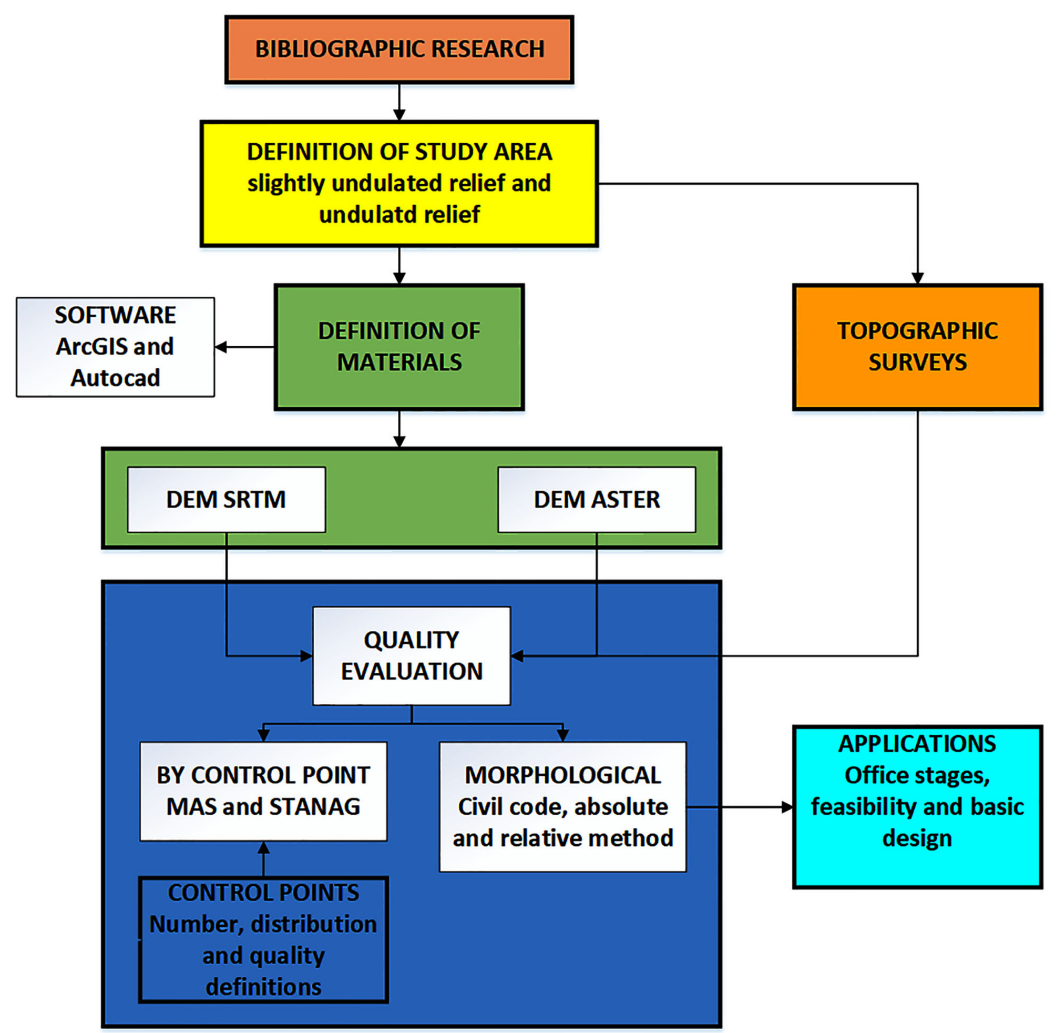

Figure 3. Flowchart of the method.

\section{Results}

This section contains the results obtained from the evaluation stages per control point and from the morphological evaluation as well as the analyses of the products quality, their matching points and applications.

\subsection{Quality Evaluation per Control Point}

As the SRTM DEM has a reported altimeter accuracy (a priori) of $16 \mathrm{~m}$ (according to item 2.5), a value that can be considered as one-half equidistance on contour line, for calculation of the expected accuracy and SE, its compatible scale will be taken into consideration, i.e. 1:80,000. The a priori expected accuracy and SE for the tested SRTM bases are shown in Table 4.

As the ASTER DEM has a reported altimeter accuracy (a priori) of $20 \mathrm{~m}$ (according to item 2.6), a value that can be considered as one-half equidistance on the contour, for calculation of expected accuracy and SE, its compatible scale will be taken into consideration, i.e. 1:100,000. The a priori expected accuracy and SE for the tested ASTER bases are shown in Table 5.

Each study area has a specific flood altitude called Flood Level (FL). For the PSJHPP, the FL considered was $128.5 \mathrm{~m}$, and for the SDHPP the FL was $345 \mathrm{~m}$. The information provided by the field topography generated altimetric bases which, due to their high accuracy, were utilized as reference for the extraction of the control points used in this study. 
Table 4. Expected accuracy and SE (MAS) for the SRTM DEM.

\begin{tabular}{cccc}
\hline Scale 1:80,000 & Class A & Class B & Class C \\
\hline Accuracy $(\mathrm{m})$ & 16 & 19.2 & 24 \\
SE $(\mathrm{m})$ & 10.66 & 12.8 & 16 \\
\hline
\end{tabular}

Table 5. Expected accuracy and SE (MAS) for ASTER DEM.

\begin{tabular}{cccc}
\hline Scale 1:100,000 & Class A & Class B & Class C \\
\hline Accuracy $(\mathrm{m})$ & 20 & 24 & 30 \\
SE $(\mathrm{m})$ & 13.33 & 16 & 20 \\
\hline
\end{tabular}

After the coordinates derived from the surveys were entered into a graphical environment (Autodesk Map), they went through an editing process and were converted into digital vectoral files in DXF format and were called Reference Base 1 for PSJHPP, Reference Base 2 for SDHPP.

The $181 \mathrm{~km}$ of the PSJHPP were transformed into a $7251 \mathrm{X} 3$ spreadsheet, that is, 7251 lines (points) and 3 columns (coordinates: east, north and altitude). The $75 \mathrm{~km}$ of the SDHPP became a 3529 X 3 spreadsheet. The 40 control points selected by draw were distributed and inserted into the bases, per study area, as shown in Figure 4 and Figure 5.

The location of the 40 points for each reference base was analyzed in relation to the contours of each based tested and followed by interpolation. The mean differences of the 40 points of SRTM and ASTER bases for each studied area can be seen in Table 6 .

Hypothesis testing was applied to check for systematic trends for the dataset with 39 degrees of freedom and confidence intervals of $90 \%, 95 \%$ and $98 \%$, both to " $\mathrm{t}$ " and " $\mathrm{z}$ " statistics, in this case using the values of MAS, Class A Standard, for the products' declared SE as population standard deviation. The calculated values for both statistics for statistics are shown in Table 7 .

According to what is shown in Table 7, the hypothesis that the bases could be considered as free from systematic trends was rejected. The 90\%, 95\% and 97.5\% confidence intervals of both Normal distribution of $1.29,1.65$ and 1.96 and T-Student distribution of 1303, 1684 and 2021 are lower than the required values (in module), thus indicating a systematic trend. By using basic arithmetic, the systematic errors were extracted from each tested base.

The new difference means for the 40 points of the SRTM and ASTER bases, after removal of systematic trend for each study area, can be seen in Table 8 .

\section{1) Evaluation according to MAS}

The four highest altitude differences were not considered for calculation of MAS (four points out of 40). The fifth highest value in descending order was considered threshold, i.e., the accuracy value. Based on these criteria, the MAS values obtained are described in Table 9, for the SRTM bases, and in Table 10 for the ASTER bases. 


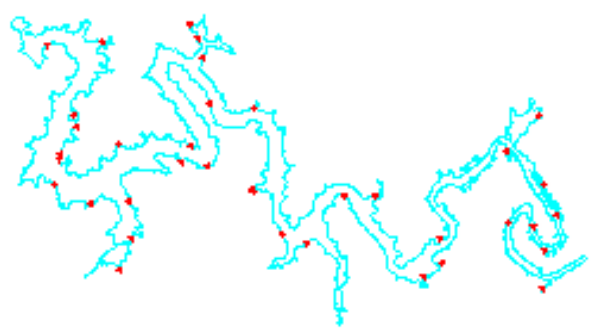

Figure 4. PSJHPP: Distribution of control points.

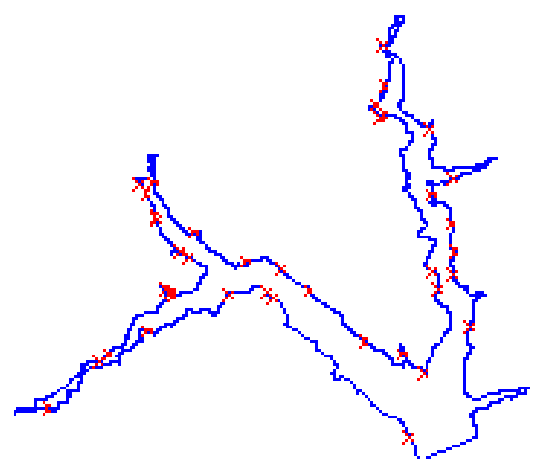

Figure 5. SDHPP: Distribution of control points.

Table 6. Mean and standard deviation of the differences between the reference bases and tested bases.

\begin{tabular}{ccc}
\hline Base & Mean $(\mathrm{m})$ & Standard deviation $(\mathrm{m})$ \\
\hline SRTM 1 & -7.48 & 4.77 \\
SRTM 2 & -6.49 & 3.24 \\
ASTER 1 & -5.45 & 8.82 \\
ASTER 2 & -8.16 & 3.55 \\
\hline
\end{tabular}

Table 7. Calculation results-Trend analysis.

\begin{tabular}{ccc}
\hline Bases/Distributions & T-Student & Normal \\
\hline SRTM Base 1 & -11.29 & -4.99 \\
SRTM Base 2 & -18.58 & -5.57 \\
ASTER Base 1 & -10.43 & -6.81 \\
ASTER Base 2 & -21.08 & -5.55 \\
\hline
\end{tabular}

Table 8. Mean and standard deviation of the differences between the reference bases and tested bases-with no trend.

\begin{tabular}{ccc}
\hline Base & Mean $(\mathrm{m})$ & Standard Deviation $(\mathrm{m})$ \\
\hline SRTM 1 & 0.02 & 4.77 \\
SRTM 2 & 0.01 & 3.24 \\
ASTER 1 & -0.45 & 8.82 \\
ASTER 2 & -0.16 & 3.55 \\
\hline
\end{tabular}


Table 9. Accuracy and SE (MAS) for SRTM—scale 1:80,000.

\begin{tabular}{cccc}
\hline Base & Standard & Accuracy & SE \\
\hline PSJHPP & Class A & 12.5 & 4.77 \\
SDHPP & Class A & 10 & 3.24 \\
\hline
\end{tabular}

Table 10. Accuracy and SE (MAS) for ASTER—scale 1:100,000.

\begin{tabular}{cccc}
\hline Base & Standard & Accuracy & SE \\
\hline PSJHPP & Class A & 16 & 8.82 \\
SDHPP & Class A & 14 & 3.55 \\
\hline
\end{tabular}

By observing the values described in Table 9, it can be concluded that the SRTM Bases PSJHPP and SDHPP met MAS-Class A standard for altimetry with regard to accuracy and SE. By observing the values described in Table 10, it can be concluded that both ASTER bases met MAS-Class A standard for altimetry with regard to accuracy and SE.

Taking into account the systematic trend shown in Table 6, after the trend removal, the MAS values are obtained, which are shown in Table 11 for the SRTM bases, and in Table 12 for the ASTER bases.

By observing the values of Table 11, it can be concluded that both SRTM bases had an increase in their scale and could then meet MAS-Class A standard for altimetry with better accuracy values when compared with the values shown in Table 9.

By observing the values of Table 12, it can be concluded that the ASTER Base of SDHPP has an increase in its scale and could then meet MAS-Class A Standard for altimetry with better accuracy values when compared with the values shown in Table 10. The ASTER Base of PSJHPP continued to meet the standard with the same accuracy as before.

\section{2) Evaluation according to STANAG 2215}

At this stage, the evaluation was also performed by extracting the planialtimetric points in the terrain and the respective inclusion of the horizontal coordinates of these points into the generated products. To fit the product into STANAG, thus, in a given altimetry class, it was verified whether $90 \%$ (ninety percent) of the points were within the contour intervals described in Table 3.

In the same way as of item 4.1.a), for calculation of the expected accuracy and SE with regard to the STANAG of SRTM, the scale 1:80,000 and 1:100,000 for ASTER was considered. The a priori expected accuracy for the SRTM and ASTER DEM bases tested are described in Table 13 and Table 14.

Based specifically on the five greatest altitude differences, where the values with results above $10 \%$ maximum (four points out of 40 ) were disregarded, the fifth highest value in descending order is considered threshold, i.e., the accuracy value. Based on these values, the resulting STANAG values are presented in Table 15, for the SRTM bases, and in Table 16 for the ASTER bases. 
Table 11. Accuracy and SE (MAS) for SRTM.

\begin{tabular}{ccccc}
\hline Base & Standard & Accuracy & SE & Scale \\
\hline PSJHPP & Class A & -5.5 & 4.77 & $1: 37,500$ \\
SDHPP & Class A & -4.89 & 3.24 & $1: 25,000$ \\
\hline
\end{tabular}

Table 12. Accuracy and SE (MAS) for ASTER.

\begin{tabular}{ccccc}
\hline Base & Standard & Accuracy & SE & Scale \\
\hline PSJHPP & Class A & -15.93 & 8.82 & $1: 80,000$ \\
SDHPP & Class A & 5.57 & 3.55 & $1: 30,000$ \\
\hline
\end{tabular}

Table 13. Expected accuracy and SE (STANAG) for SRTM DEM.

\begin{tabular}{cccc}
\hline Scale 1:80,000 & Class 0 & Class 1 & Class 2 \\
\hline Accuracy $(\mathrm{m})$ & 8 & 16 & 32 \\
\hline
\end{tabular}

Table 14. Expected accuracy and SE (STANAG) for ASTER DEM.

\begin{tabular}{cccc}
\hline Scale 1:100,000 & Class 0 & Class 1 & Class 2 \\
\hline Accuracy $(\mathrm{m})$ & 10 & 20 & 40 \\
\hline
\end{tabular}

Table 15. Accuracy and SE (STANAG) for SRTM DEM-Scale 1:80,000.

\begin{tabular}{cccc}
\hline Base & Standard & Accuracy & SE \\
\hline PSJHPP & Class 1 & 16 & 4.77 \\
SDHPP & Class 1 & 16 & 3.24 \\
\hline
\end{tabular}

Table 16. Accuracy and SE (STANAG) for ASTER DEM-Scale 1:100,000.

\begin{tabular}{cccc}
\hline Base & Standard & Accuracy & SE \\
\hline PSJHPP & Class 1 & 20 & 8.82 \\
SDHPP & Class 1 & 20 & 3.55 \\
\hline
\end{tabular}

By observing the values contained in Table 15, it can be concluded that the SRTM of the PSJHPP and SDHPP bases followed STANAG-Class 1 standard for altimetry with respect to accuracy. By observing the values shown in Table 16, it can be concluded that both ASTER Bases met STANAG-Class 1 standard for altimetry with respect to accuracy.

Considering the systematic trend shown in Table 7 , after removal of the trend, the STANAG values were obtained, which are described in Table 17 for the SRTM bases and in Table 18 for the ASTER bases.

By observing the values described in Table 17, it can be concluded that all SRTM Bases had an increase in their scale and could then meet STANAG-Class 1 standard for altimetry with better accuracy values when compared with the 
ones shown in Table 9. By observing the values shown in Table 18, it can be concluded that the ASTER Base of SDHPP had an increase in its scale and could then meet STANAG-Class 1 standard for altimetry with better accuracy values when compared with the ones of Table 10. The ASTER base of PSJHPP remained within the standard with the same previous accuracy.

\subsection{Morphological Evaluation}

The relief inclination/slope of each studied area was characterized based on the contour lines of each base tested. To this end, the Equations (1) and (2) were applied, resulting in the slope and inclination values described in Table 19.

According to the classifications developed by [21] and the values shown in Table 19, the relief of the PSJHPP was classified as undulated, with slopes ranging from $8 \%$ to $20 \%$. The SDHPP relief, in turn, was classified as gently undulated, with slopes between $3 \%$ and $8 \%$.

For the evaluation based on the Brazil Civil Code, the actual dimensions measured on field, as provided by Reference Bases 1 and 2, based on the project FL of PSJHPP and SDHPP, were used. The dimensions of the Reference Bases are shown in Table 20.

The simulated dimensions correspond to the curves generated from the tested bases at the FL altitudes.

Table 21 contains the dimensions formed by the simulated contours for each simulated area and base.

For each study area, the contour lines that re-simulated the flood levels (FL) after removal of the systematic trend were extracted from the SRTM DEM and ASTER DEM. The contour line of $135 \mathrm{~m}$ of the SRTM and ASTER bases for PSJHPP, of $350 \mathrm{~m}$ for the SRTM base, and contour of $352 \mathrm{~m}$ of the ASTER base for SDHPP were also extracted. Table 22 contains the dimensions formed by the re-simulated curves for each area and DEM.

To calculate the absolute dimensions, basic arithmetic was used by first subtracting the values for the simulated bases, of FL and SI, as shown in Table 20 and Table 21. The calculation resulted in the dimensions shown in Table 23.

Afterwards, the same procedure was conducted between the re-simulated values of Table 20 and Table 22. The calculation resulted in the dimensions shown in Table 24.

To calculate the relative dimensions, the Equations (3) and (4) were used first, resulting in the CA and TA dimensions. Subsequently, the basic arithmetic was used by subtracting the values of the calculated TA and CA. The final calculation resulted in the dimensions presented first in Table 25, for the simulated values, with their respective percentages shown in Table 27.

Afterwards, the same calculations were done for the re-simulated values, which are shown in Table 26, with their respective percentages presented in Table 28. The values presented in the cited Tables represent the areas that are not common between the FL Bases and SI bases. 
Table 17. Accuracy and SE (STANAG) for SRTM DEM.

\begin{tabular}{ccccc}
\hline Base & Standard & Accuracy & SE & Scale \\
\hline PSJHPP & Class 1 & 7.5 & 4.77 & $1: 37,500$ \\
SDHPP & Class 1 & 5.0 & 3.24 & $1: 25,000$ \\
\hline
\end{tabular}

Table 18. Accuracy and SE (STANAG) ASTER DEM.

\begin{tabular}{ccccc}
\hline Base & Standard & Accuracy & SE & Scala \\
\hline PSJHPP & Class 1 & 16.00 & 8.82 & $1: 80,000$ \\
SDHPP & Class 1 & 6.0 & 3.55 & $1: 30,000$ \\
\hline
\end{tabular}

Table 19. Inclination/slope for the studied areas.

\begin{tabular}{ccc}
\hline Base & Inclination (\%) & Slope (decimal degrees) \\
\hline PSJHPP & 8.50 & 4.86 \\
SDHPP & 4.00 & 2.29 \\
\hline
\end{tabular}

Table 20. Dimensions of the reference bases.

\begin{tabular}{cccc}
\hline Base & FL area $\left(\mathrm{m}^{2}\right)$ & FL perimeter $(\mathrm{m})$ & FL Altitude $(\mathrm{m})$ \\
\hline PSJHPP & $25,236,104.49$ & $181,140.46$ & 128.5 \\
SDHPP & $18,638,586.64$ & $75,744.36$ & 345 \\
\hline
\end{tabular}

Table 21. Dimensions of the simulated bases.

\begin{tabular}{cccc}
\hline Base & SI Area $\left(\mathrm{m}^{2}\right)$ & SI Perimeter $(\mathrm{m})$ & SI Altitude $(\mathrm{m})$ \\
\hline SRTM 1 & $16,388,006.99$ & $104,138.18$ & 130 \\
SRTM 2 & $10,404,358.03$ & $53,172.28$ & 345 \\
ASTER 1 & $19,314,548.58$ & $215,831.07$ & 130 \\
ASTER 2 & $5,402,843.98$ & $70,061.06$ & 345 \\
\hline
\end{tabular}

Table 22. Dimensions of re-simulated bases.

\begin{tabular}{cccc}
\hline Base & SI Area $\left(\mathrm{m}^{2}\right)$ & SI Perimeter $(\mathrm{m})$ & SI Altitude $(\mathrm{m})$ \\
\hline SRTM 1 & $29,760,808.43$ & $141,705.74$ & 135 \\
SRTM 2 & $17,358,782.48$ & $66,650.37$ & 350 \\
ASTER 1 & $32,749,947.36$ & $255,873.37$ & 135 \\
ASTER 2 & $14,879,824.78$ & $109,713.30$ & 352 \\
\hline
\end{tabular}

Table 23. Absolute area between the reference and simulated bases.

\begin{tabular}{ccc}
\hline Bases & FL - SI area $\left(\mathrm{m}^{2}\right)$ & FL-SI area $\left(\mathrm{m}^{2}\right) \%$ \\
\hline SRTM 1 & $8,848,097.50$ & 35.06 \\
SRTM 2 & $8,234,228.61$ & 44.18 \\
ASTER 1 & $5,921,555.91$ & 23.46 \\
ASTER 2 & $13,235,742.66$ & 71.01 \\
\hline
\end{tabular}


Table 24. Absolute area between the reference and re-simulated bases.

\begin{tabular}{ccc}
\hline Bases & FL - SI area $\left(\mathrm{m}^{2}\right)$ & FL-SI area $\left(\mathrm{m}^{2}\right) \%$ \\
\hline SRTM 1 & $-4,524,703.94$ & -17.93 \\
SRTM 2 & $1,279,804.16$ & 6.87 \\
ASTER 1 & $-7,513,842.87$ & -29.77 \\
ASTER 2 & $3,758,761.86$ & 20.17 \\
\hline
\end{tabular}

Table 25. Relative area and common area between the reference and simulated bases.

\begin{tabular}{ccc}
\hline Bases & TA $-\mathrm{CA}\left(\mathrm{m}^{2}\right)$ & CA $\left(\mathrm{m}^{2}\right)$ \\
\hline SRTM 1 & $12,031,968.95$ & $14,796,071.27$ \\
SRTM 2 & $8,368,499.30$ & $10,337,222.69$ \\
ASTER 1 & $14,900,962.38$ & $14,824,845.35$ \\
ASTER 2 & $13,251,920.25$ & $5,394,755.19$ \\
\hline
\end{tabular}

Table 26. Relative area and common area between the reference and re-simulated bases.

\begin{tabular}{ccc}
\hline Bases & TA - CA $\left(\mathrm{m}^{2}\right)$ & CA $\left(\mathrm{m}^{2}\right)$ \\
\hline SRTM 1 & $11,647,334.94$ & $21,674,788.99$ \\
SRTM 2 & $4,102,713.19$ & $15,947,327.96$ \\
ASTER 1 & $17,681,809.76$ & $20,152,121.05$ \\
ASTER 2 & $6,200,024.21$ & $13,659,193.61$ \\
\hline
\end{tabular}

Table 27. Relative area (\%) and common area between the reference and simulated bases.

\begin{tabular}{ccc}
\hline Bases & TA - CA $\left(\mathrm{m}^{2}\right) \%$ & CA $\left(\mathrm{m}^{2}\right) \%$ \\
\hline SRTM 1 & 44.85 & 55.15 \\
SRTM 2 & 44.74 & 55.26 \\
ASTER 1 & 50.13 & 49.87 \\
ASTER 2 & 71.07 & 28.93 \\
\hline
\end{tabular}

Table 28. Relative area (\%) and common area between the reference and re-simulated bases.

\begin{tabular}{ccc}
\hline Bases & TA $-\mathrm{CA}\left(\mathrm{m}^{2}\right) \%$ & $\mathrm{CA}\left(\mathrm{m}^{2}\right) \%$ \\
\hline SRTM 1 & 34.95 & 65.05 \\
SRTM 2 & 20.46 & 79.54 \\
ASTER 1 & 46.74 & 53.26 \\
ASTER 2 & 31.22 & 68.78 \\
\hline
\end{tabular}

According to the dimensions shown in the column FL-SI $\left(\mathrm{m}^{2}\right)$ Area $\%$ of Table 23 and in column TA - CA $\left(\mathrm{m}^{2}\right) \%$ of Table 27, relative to the areas, for the bases tested there was a significant difference, much above the acceptable level 
(5\%), and, therefore, the Simulated Curves by SRTM and ASTER, in absolute and relative terms, are not in conformity with Article 500 of the Civil Code.

According to the dimensions presented in column FL - SI $\left(\mathrm{m}^{2}\right)$ Area\% of Table 24 and in column TA - CA $\left(\mathrm{m}^{2}\right) \%$ of Table 28 , relative to the areas, for the re-simulated bases tested, there was a significant difference, much above the acceptable level (5\%); therefore, the Re-Simulated Curves by SRTM and ASTER, in absolute and relative terms, are not in conformity with Article 500 of the Civil Code.

When the values of the simulated curves, as presented in Table 27, are compared with the values of re-simulated curves in Table 28, it can be seen that there were significant differences. In most of the re-simulated bases, the differences between the FL and SI diminished, except for the ASTER Base 1, in which the values increased in absolute terms.

By observing the results of Table 27, specifically the values in column CA $\left(\mathrm{m}^{2}\right) \%$, it can be seen that the areas formed in common in the bases tested is relatively small. Only SRTM Base 1 and SRTM Base 2 exhibited common areas slightly above $50 \%$ of their total.

By observing the results of Table 28, specifically the values in column CA $\left(\mathrm{m}^{2}\right) \%$, it can be seen that the area formed in all re-simulated bases tested enlarged, when compared with the values presented in the same column of Table 27 , exhibiting common areas above $50 \%$ in most of them.

At the quantitative morphological evaluation stage, the dimensions formed between the reference and simulated/re-simulated curves were calculated, except for the common areas formed. The results can be seen in Table 29, where in column OA\% is shown the percent value relative to the area formed between the simulated/re-simulated curve and the reference curve, considering the total value $\mathrm{TA}=\mathrm{CA}+\mathrm{OA}+\mathrm{IA}$. In column $\mathrm{OA} / \mathrm{TA} \%$ is shown the percent value relative to the area formed between the simulated/re-simulated curve, considering only the areas that are not in common with the simulated/re-simulated curves and reference curves (TA - CA). Column IA\% contains the percent value relative to the area formed between the reference curve and the simulated/re-simulated curve, considering the total value TA $=\mathrm{CA}+\mathrm{OA}+\mathrm{IA}$. In column IA/TA $\%$ is shown the percent value relative to the area formed between the reference curve and the simulated/re-simulated curve, considering only the areas that are not in common with the simulated/re-simulated curves and reference curves (TA $\mathrm{CA})$. The re-simulated bases are indicated by (R) in the "Bases" column.

By observing the results shown in Table 29, it can be seen, especially in columns OA/TA\% and IA/TA\%, that the majority of the non-common areas of the simulated bases formed were inside the reference curve, with nearly $100 \%$ of the areas formed inwardly, as were the cases of the SRTM 2 and ASTER 2 bases. This result shows a diminishing/narrowing tendency of the curve that simulates the inundation and consequent formation of islands.

Therefore, by observing the results relative to the re-simulated bases, a more homogeneous distribution of non-common areas between outside and inside of 
Table 29. Area not in common (\%) between the reference bases and simulated/resimulated bases.

\begin{tabular}{ccccc}
\hline Bases & OA\% & OA/TA\% & IA\% & IA/TA\% \\
\hline SRTM 1 & 5.93 & 13.23 & 38.91 & 86.77 \\
SRTM 1 (R) & 24.27 & 69.42 & 10.69 & 30.58 \\
SRTM 2 & 0.36 & 0.80 & 44.38 & 99.20 \\
SRTM 2 (R) & 7.04 & 34.40 & 13.42 & 65.60 \\
ASTER 1 & 15.10 & 30.13 & 35.02 & 69.87 \\
ASTER 1 (R) & 33.30 & 71.25 & 13.44 & 28.75 \\
ASTER 2 & 0.04 & 0.06 & 71.03 & 99.94 \\
ASTER 2 (R) & 6.15 & 19.69 & 25.07 & 80.31 \\
\hline
\end{tabular}

the reference curve can be seen. At the SRTM 1 and ASTER 1 bases, for instance, the non-common areas formed are outside the reference. The opposite, that is, areas formed inside occurred at the SRTM 2 and ASTER 2 bases.

Details of each study area and simulated/re-simulated bases can be seen in Figures 6-13, where the white drawings represent areas formed in common (CA) between the reference and simulated/re-simulated curves, and the red drawings represent the non-common areas formed between the reference and simulated/re-simulated curves (OA and IA).

At the qualitative morphological evaluation stage, with regard to the study area 1, which has an undulated relief, the results of the simulated curves generated by the DEM both for SRTM Base 1 and ASTER Base 1 are justified because the steeper relief diminishes the lateral spacing (distance) between the contour lines. The simulated curves followed, only partially, the reference curve drawing, especially in the dam region, and for most of its contour it was morphologically different from the reference curve, varying downward, and aggravated by the fact that, far from the dam, small islands were generated. These results are in disagreement with the rating of these bases as MAS Class A Standard, as described in section 4.1.a), because the test only enabled an assessment based on points, between contour lines, and the value given to the point was the same as the last contour generated before the "water body" feature was mapped by the sensor.

With respect to the study area 2 , which has a gently undulating relief, the results generated by the simulated curve extracted from the DEM of the SRTM Base 2, are justified because the DEM seemed to be best suited to flat reliefs, reflecting the contour of the simulated curve, which was morphologically in accordance with the reference curve, especially in places closer to the dam. Far from the dam, the simulated curve varied downwards. Extraction of the simulated curve for the altitude of $345 \mathrm{~m}$ generated by this base, exactly at the flood altitude, might have contributed positively to its contour formation. This result seems to be consistent with the ones that rated SRTM Base 2 into the Mass Class 
A standard, as described in 4.1.a), because the testing, despite enabling only a points-based evaluation between contour lines, was compatible with the contour of the SRTM-generated curve.

Also, with regard to the study area 2, but relative to the DEM of ASTER Base 2 , the results are justified because the DEM seems not to match perfectly the

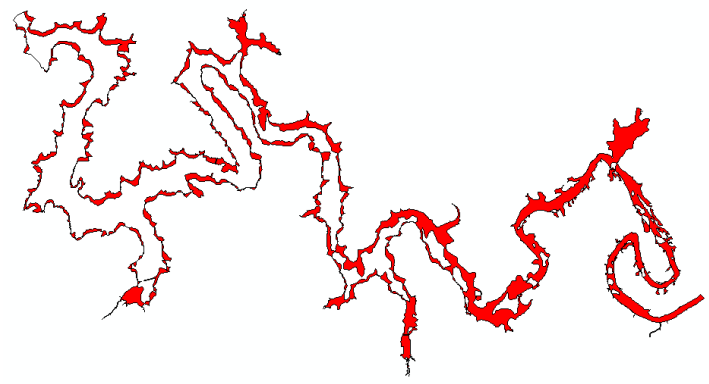

Figure 6. PSJHPP: SRTM 1 simulation.

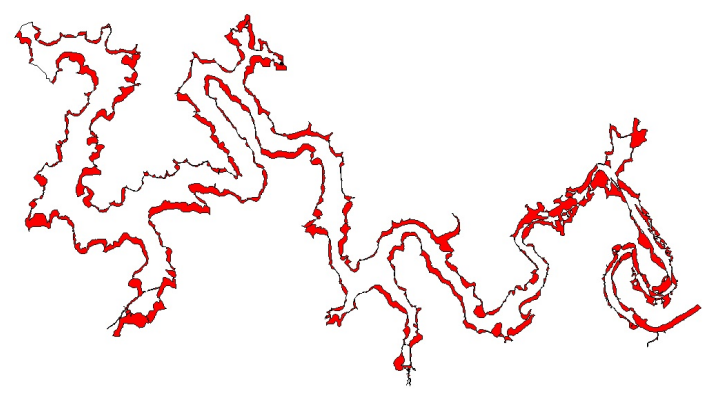

Figure 7. PSJHPP: SRTM 1 Re-simulation.

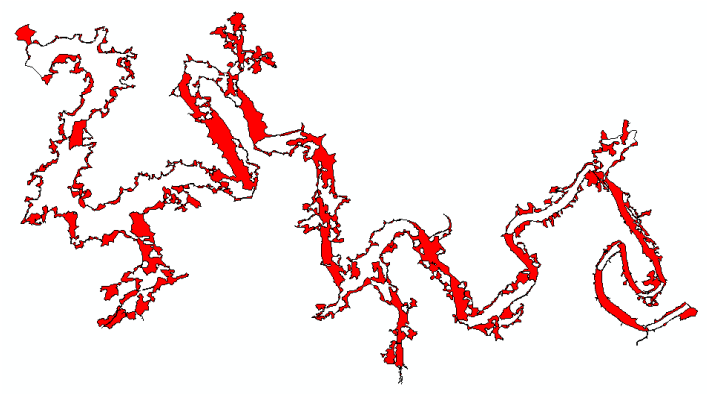

Figure 8. PSJHPP: ASTER 1 simulation.

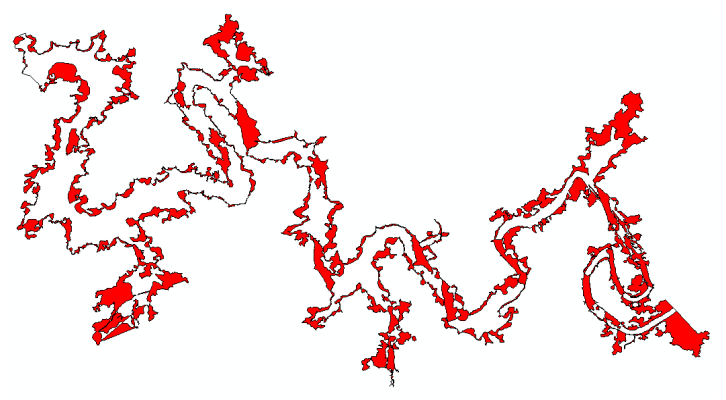

Figure 9. PSJHPP: ASTER 1 Re-simulation. 


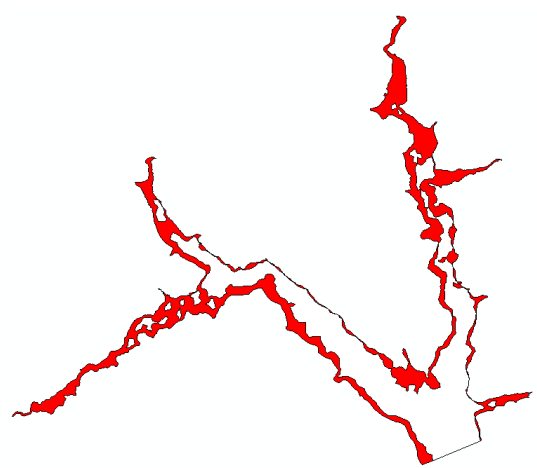

Figure 10. SDHPP: SRTM 2 simulation.

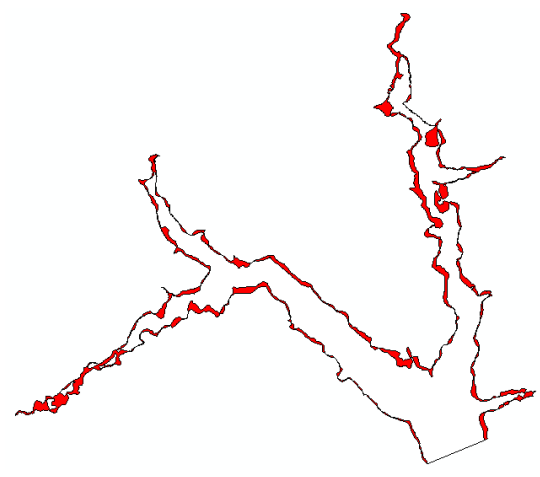

Figure 11. SDHPP: SRTM 2 Re-simulation.

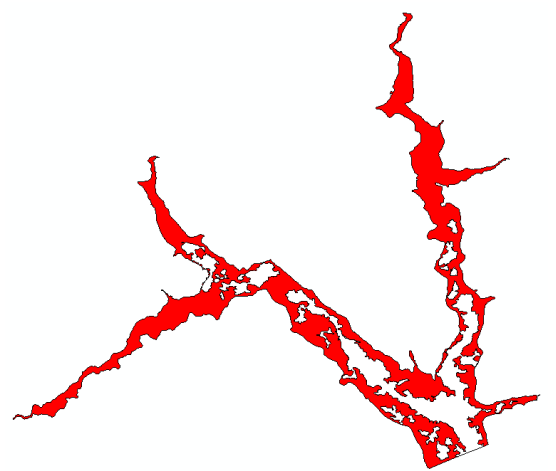

Figure 12. SDHPP: ASTER 2 simulation.

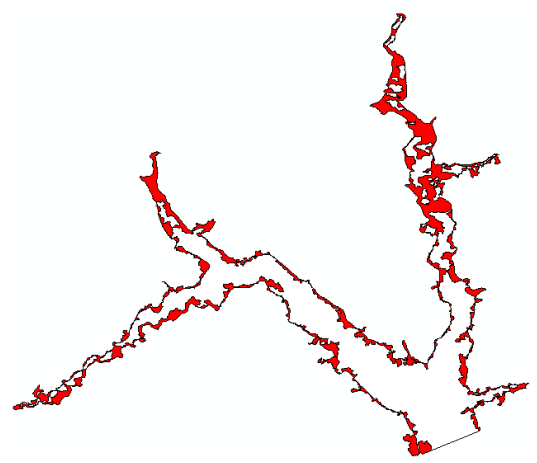

Figure 13. SDJHPP: ASTER 2 Re-simulation. 
reference curve contour, being morphologically smaller and often inside the same for the most part of its contour. The simulated contour line does not follow most of the reference curve outline, not even in the dam region, varying downwards along almost its entire contour, and aggravated by the fact of generating numerous islands. This result seems not to be consistent with the rating of ASTER Base 2 as MAS Class A standard, as described in item 4.1.a), because the testing, despite allowing only a points-based evaluation, between contour lines, does not reflect the reality of the ASTER-generated curve contour.

For both study areas and tested bases, the inconsistencies in absolute and relative forms in relation to the Civil Code, evaluations already described in Section 4.2 , seem compatible with the results obtained in the quality morphological evaluation.

\subsection{Applications}

First, the results were applied to the M\&P indicator. The reference values are described in Table 30.

For each tested base, an indicator was calculated based on the extracted curve that simulates/re-simulates the flood. The calculated indicators are described in Table 31, with its respective percentage of $20 \%$.

According to the values presented in Table 31, there was a significant difference in the indicators calculated for both simulated bases when compared with the reference values shown in Table 30, and the simulated curves from SRTM and ASTER were not within the established limit.

However, according to the values presented in the same table for the re-simulated bases $(\mathrm{R})$, there was no significant difference for the calculated indicators

Table 30. M\&P indicator for the reference bases.

\begin{tabular}{cccc}
\hline Power Plant & Output $(\mathrm{kW})$ & FL area (ha) & Indicator \\
\hline PSJHPP & 77,000 & 2523.61 & 30.51 \\
SDHPP & 48,000 & 1863.86 & 25.75 \\
\hline
\end{tabular}

Table 31. M\&P indicator (Ind.) for the bases tested.

\begin{tabular}{ccccc}
\hline Power Plant & Output $(\mathrm{kW})$ & SI area (ha) & Ind. & Ind.\% \\
\hline SRTM 1 & 77,000 & 1638.80 & 46.98 & 54.00 \\
SRTM 1 (R) & 77,000 & 2976.08 & 25.87 & -15.20 \\
SRTM 2 & 48,000 & 1040.43 & 46.13 & 79.16 \\
SRTM 2 (R) & 48,000 & 1735.88 & 27.65 & 7.38 \\
ASTER 1 & 77,000 & 1931.45 & 40.23 & 39.87 \\
ASTER 1 (R) & 77,000 & 3274.99 & 23.51 & -22.94 \\
ASTER 2 & 48,000 & 540.284 & 88.84 & 245.02 \\
ASTER 2 (R) & 48,000 & 1487.98 & 32.26 & 25.27 \\
\hline
\end{tabular}


when compared with the reference values described in Table 30, and the resimulated curves from SRTM 1 and SRTM 2 bases were within the established limit.

ASTER 1 and ASTER 2 bases, although having lower values than the values calculated from the simulated bases, remained outside the $20 \%$ limit established.

The second application was related to the stages of hydroelectric projects, as follows:

- As the SRTM Base 1 curve for the simulated height of $130 \mathrm{~m}$ virtually does not follow the reference curve and indicates great downward discrepancies and the formation of islands, with only $55.15 \%$ of common areas in relation to the total areas, a non-homogeneous distribution of non-common areas (13.23\% OA and $86.77 \%$ IA), with most of the non-common areas inside the reference curve, as shown in Table 27 and Table 29, it can be concluded that the simulated curve cannot be used to simulate a flood area at any stage of a HPP project;

- As the curve of the SRTM Base 1 for the re-simuated height of $135 \mathrm{~m}$, in turn, follows most of the reference curve line and indicates formation of some islands, with $65.05 \%$ of common areas in relation to the total and a slightly more homgeneous distribtuion of non-common areas $(69.42 \% \mathrm{OA}$ and $30.58 \%$ IA) with most of non-common areas outside the curve, as shown in Table 27 and Table 29, it can be concluded that the re-simulated curve can be used from the Estimation of Hydroeletric Output stage to the Hydroelectric Inventory stage;

- As the ASTER Base 1 curve for the simulated altitude of $130 \mathrm{~m}$ virtually does not follows the reference curve and indicates great downward discrepancies and formation of inslands, with common areas for only $49.87 \%$ of the total, a non-homogeneous distribution of non-common areas $30.13 \%$ OA and $69.87 \%$ IA), with most of non-common areas within the reference curve, as shown in Table 27 and Table 29, it can be concluded that the simulated curve cannot be used to simulate a flood area at any stage of a HPP project;

- As the ASTER Base 1 curve for the re-simulated height of $135 \mathrm{~m}$, in turn, follows most of the reference curve, but indicates formation of some islands, with $53.26 \%$ of common areas in relation to the total, and a non-homogeneous distribution of non-common areas (71.25\% OA and $28.75 \%$ IA) and the majority of non-common areas outside the reference curve, as shown in Table 27 and Table 29, it can be concluded that the re-simulated curve can be used from the Estimation of Hydroelectric Output stage to the first stage, Study Planning, of the Hydroelectric Inventory stage;

- As the SRTM Base 2 curve for the simulated altidude of $345 \mathrm{~m}$ virtually does not follow the reference curve and indicates great downward discrepancies and islands formation, with only $55.26 \%$ of common areas in relation to the 
total, with non-homogeneous distribution of non-common areas $(0.80 \% \mathrm{OA}$ and $99.20 \%$ IA) with most of the non-common areas within the reference curve, as shown in Table 27 and Table 29, it can be concluded that the simulated curve cannot be used to simulate a flood area at any stage of a HPP project;

- As the SRTM Base 2 curve for the re-simulated height of $350 \mathrm{~m}$, in turn, follows most of the reference curve, both in an out the reference curve, with $79.54 \%$ of common areas in relation to the total, with no indication of islands formation, and a slightly more homogeneous distribution of non-common areas $(34.40 \% \mathrm{OA}$ and $65.60 \%$ IA), even with most of non-common areas within the reference curve, as shown in Table 27 and Table 29, it can be concluded that the re-simulated curve can be used from the Estimation of Hydroelectric Output stage to the Feasibility stage;

- As the ASTER Base 2 curve for the simulated height of $350 \mathrm{~m}$ virtually does not follow the reference curve and indicates great downard discrepancies and islands formation, with only $28.93 \%$ of common areas in relation to the total, a non-homogeneous distribution of non-common areas $(0.06 \% \mathrm{OA}$ and 99.94\% IA) with most of the non-common areas within the reference curve, as shown in Table 27 and Table 29, it can be concluded that the simulated curve cannot be used to simulate the flood area at any stage of the project of a hydroelectric power plant;

- As the ASTER Base 2 curve for the re-simulated height of $352 \mathrm{~m}$, in turn, follows partially the reference curve and indicates formation of islands, with $68.78 \%$ of common areas in relation to the total and a non-homogeneous distribution of non-common areas (19.69\% OA and $80.31 \%$ IA), even with most of the non-common areas within the curve, as shown in Table 27 and Table 29, it can be concluded that the re-simulated curve can be used from the Estimation of Hydroelectric Output stage to the Hydroelectric Inventory stage.

\section{Conclusions and Recommendations}

It can be concluded that the main objective was achieved considering that a method based on points was proposed to perform the evaluation of the altimetry quality of altimetric bases and to extract contour lines that simulate the FL, indicating their real differences in areas. The GIS-developed method was applied in two study areas with different reliefs.

For the SRTM Base 1, which has quality compatible with scale 1:80,000 of MAS Class A Standard, the simulated altitude of $130 \mathrm{~m}$, with its respective inherent systematic error, was not approved for simulations of the flood level of the Passo São João HPP. But for the re-simulated height of $135 \mathrm{~m}$, with removal of systematic trend, it was approved to simulate the flood level of $128.5 \mathrm{~m}$ up to the Hydroelectric Inventory stage. It can be concluded that for the same conditions of undulated relief and for the same kind of base, a re-simulation of the flood 
height can be done.

For ASTER Base 1, which has quality compatible with scale 1:100,000 of MAS Class Standard, the simulated height of $130 \mathrm{~m}$, with its respective inherent systematic error was not approved for simulation of the flood level of the Passo São João HPP. On the other hand, the simulated altitude of $135 \mathrm{~m}$, after removing the systematic trend, was approved for simulation of flood height of $128.5 \mathrm{~m}$ up to the first stage of the Hydroelectric Inventory, that is, the Study Planning. It can be concluded that, in the same conditions of undulated relief and for the same kind of base, altitude re-simulation can be performed.

For SRTM Base 2, which has quality compatible with scale 1:80,000 of MAS Class A Standard, the simulated height of $345 \mathrm{~m}$, with its respective inherent systematic error, was not approved for simulation of the flood level of the São Domingos HPP. On the other hand, the re-simulated altitude of $350 \mathrm{~m}$, after removing the systematic trend, was approved for simulation of the flood height of $345 \mathrm{~m}$ up to the Feasibility stage. It can be concluded that, in the same conditions of slightly undulated relief and for the same kind of base, re-simulation of flood height can be performed.

For ASTER Base 2, which has quality compatible with scale 1:100,000 of MAS Class A Standard, the simulated altitude of $345 \mathrm{~m}$, with its respective inherent systematic error, was not approved for simulation of the flood level of the São Domingos HPP. The re-simulated altitude of $352 \mathrm{~m}$, in turn, after removing the systematic trend, was approved for simulation of a flood height of $345 \mathrm{~m}$ up to the Hydroelectric Inventory stage. It can be concluded that, for the same slightly undulated relief conditions and for the same kind of base, re-simulation of flood height can be performed.

In bases where altitudes are extracted from SRTM models, after removal of the inherent systematic error found in the product (around -7.3), in slightly undulated and undulated reliefs, quality can be assured for levels between $65 \%$ and $79 \%$ of the common areas in the flood height simulation.

In bases where the altitudes are extracted from ASTER, after removal of the inherent systematic error found in the product (around -6.2), in slightly undulated and undulated reliefs, quality can be assured for levels between $53 \%$ and $68 \%$ of common areas in the flood height simulation.

It is a limitation of this study not to have performed the quality assessment by the same point and morphological method study areas that had flat and/or strongly wavy reliefs.

It is recommended to conduct studies using the method described in this paper to assess areas with plane relief, highly undulated and steep reliefs, as well as the use of other products for the same areas tested, e.g., laser scanning, stereoscopic models derived from remote sensing images or radar missions or provided by remotely-piloted air-crafts.

For other applications, such as landslides or inundations, more in-depth studies are recommended. 


\section{Conflicts of Interest}

The author declares no conflicts of interest regarding the publication of this paper.

\section{References}

[1] Celestino, V.S. (2014) Considerações sobre a qualidade altimétrica para projetos de usinas hidrelétricas. PhD Thesis, Universidade Federal de Santa Catarina, Florianópolis.

[2] Goldemberg, J. and Lucon, O. (2008) Energia, Meio Ambiente e Desenvolvimento. Edusp, São Paulo.

[3] Moreira, J.R. and Poole, A.D. (1993) Hydropower and It's Constraints. In: Johansson, T.B., et al., Eds., Renewable Energy, Island Press, Washington DC, Chapter 2, 73-119.

[4] Agência Nacional de Energia Elétrica (ANEEL) (2008) Atlas de Energia Elétrica do Brasil. 3th Edition, ANEEL, Brasília.

[5] Celestino, V.S. and Philips, J.W. (2015) Avaliação altimétrica para projetos de usinas hidrelétricas. Revista Brasileira de Cartografia, 67, 507-525.

[6] Barros, R.S. and Cruz, C.B.M. (2007) Avaliação da altimetria do modelo digital de elevação do SRTM. In: Proceedings of the 13 th Simpósio Brasileiro de Sensoriamento Remoto (SBSR), Instituto Nacional de Pesquisas Espaciais (INPE), Florianópolis, $1243-1250$.

[7] Ludwig, R. and Schneider, P. (2006) Validation of Digital Elevation Models from SRTM X-SAR for Applications in Hydrologic Modeling. Journal of Photogrammetry \& Remote Sensing, 60, 339-358. https://doi.org/10.1016/j.isprsjprs.2006.05.003

[8] Pinheiro, E.S. (2006) Comparação entre dados altimétricos Shuttle Radar Topography Mission, cartas topográficas e GPS: Numa área com relevo escarpado. Revista Brasileira de Cartografia, 58, 1-9.

[9] Rodrigues, T.L., Debiasi, P. and Souza, R.F. (2010) Avaliação da adequação dos produtos ASTER GDEM no auxílio ao mapeamento sistemático brasileiro. In: Proceedings of the 3rd Simpósio Brasileiro de Ciências Geodésicas e Tecnologias da Geoinformação, Universidade Federal de Pernambuco, Recife, 1-5.

[10] Chrysoulakis, N., Abrams, M., Kamarianakis, Y. and Stanislawski, M. (2011) Validation of ASTER GDEM for the Area of Greece. Photogrammetric Engineering \& Remote Sensing, 77, 157-165. https://doi.org/10.14358/PERS.77.2.157

[11] Luana, S., Hou, X. and Wang, Y. (2015) Datasets for the Coastal Zone of Shandong Province. Polish Maritime Research, 22, 15-20.

https://doi.org/10.1515/pomr-2015-0026

[12] Oliveira, G.C. (2015) Precisão de Modelos Digitais de Terreno, Mapeamento. Automático de Apps em Topos de Morros e a Eficácia do Novo Código Florestal. Master's Degree, Dissertation, Universidade Federal de Viçosa, Viçosa.

[13] Morais, J.D., Faria, T.S., Elmiro, M.A.T., Nero, M.A., Silva, A.A. and Nobrega, R.A.A. (2017) Altimetry Assessment of ASTER GDEM v2 and SRTM v3 Digital Elevation Models: A Case Study in Urban Area of Belo Horizonte, MG, Brazil. Boletim de Ciências Geodésicas, 23. https://doi.org/10.1590/s1982-21702017000400043

[14] Dias, M.F., Miceli, B.S., Seabra, F.M., Santos, P.R.A. and Fernandes, M.C. (2011) Avaliação Vertical de Modelos Digitais de Elevação (DEMs) em Diferentes Configurações Topográficas para Médias e Pequenas Escalas. In: Proceedings of the 15 th 
Simpósio Brasileiro de Sensoriamento Remoto (SBSR), Instituto Nacional de Pesquisas Espaciais (INPE), Curitiba, 4110-4117.

[15] Ferreira, G.F. (2014) Emprego de simulação no controle de qualidade em cartografia aplicado a modelos digitais de superfícies oriundos de sensores orbitais segundo PEC-PCD. Master's Degree, Dissertation, Universidade Federal de Pernambuco, Recife.

[16] Faria Filho, R.F. (2007) Avaliação do Potencial Hidráulico em Bacias Hidrográficas por meio de Sistemas de Informações Geográficas. Master's Degree, Dissertation, Universidade Federal de Viçosa, Viçosa.

[17] Eletrobras Centrais Elétricas (1997) Instruções para Estudos de Viabilidade. Eletrobras Centrais Elétricas, Rio de Janeiro.

[18] Eletrobras Centrais Elétricas (2000) Diretrizes para Projetos de PCH. Eletrobras Centrais Elétricas, Rio de Janeiro.

[19] Eletrobras Centrais Elétricas (2007) Manual de Inventário Hidroelétrico de Bacias Hidrográficas. Eletrobras Centrais Elétricas, Rio de Janeiro.

[20] Carvalho, C.S., Macedo, E.S. and Ogura, A.T. (2007) Mapeamento de Riscos em Encostas e Margem de Rios. Ministério das Cidades, Instituto de Pesquisas Tecnológicas (IPT), Brasília.

[21] Lemos, R.C. and Santos, R.D. (1984) Manual de descrição e coleta de solo no campo. SBCS/SNLCS, Campinas.

[22] Celestino, V.S., Rocha, R.S., Silva, R.R. and Matsuoka, C.T. (2005) Investigação geométrica para aplicação de imagens orbitais na retificação e geração de produtos cartográficos. In: Proceedings of the 22nd Congresso Brasileiro de Cartografia, Sociedade Brasileira de Cartografia (SBC), Macaé, nonpaged.

[23] Brasil: Decreto no 89.817, de 20 de junho de 1984 (1984) Estabelece as instruções reguladoras das Normas Técnicas da Cartografia Nacional. Diário Oficial da União (DOU), Brasília.

[24] Brasil: Portaria no 014, de 28 de abril de 2014 (2014) Especificação Técnica para Produtos de Conjuntos de Dados Geoespaciais. Departamento de Ciência e Tecnologia, Brasília.

[25] Nato Standardization Agency (NSA) (2001) Evaluation of Land Maps, Aeronautical Charts and Digital Topographic Data, STANAG (Standardization Agreement) No. 2215. 6th Edition, NATO, Brussels.

[26] Brasil: Lei no 10.406, de 10 de Janeiro de 2002 (2002) Código Civil Brasileiro. Diário Oficial da União (DOU), Brasília.

[27] Pereira, R. (1978) A estatística e suas aplicações. Grafosul, Porto Alegre.

[28] Afonso, A.J.G., Dias, R.F.C. and Teodoro, R.F. (2006) IGeoE: Positional Quality Control in the 1/25000 Cartography. Proceedings of the 7 th International Symposium on Spatial Accuracy Assessment in Natural Resources and Environmental Sciences, 5-7 July 2006, 835-839.

[29] Hutchinson, M.F., Stein, J.A., Stein, J.L. and Xu, T. (2009) Locally Adaptive Gridding of Noisy High Resolution Topographic Data. Proceedings of the 18 th World IMACS/MODSIM Congress, Cairns, 13-17 July 2009, 2493-2499.

[30] Jet Propulsion Laboratory (JPL) (2019) Shuttle Radar Topography Mission (SRTM). https://www.jpl.nasa.gov

[31] Jet Propulsion Laboratory (JPL) (2019) U.S. Releases Enhanced Shuttle Land Elevation Data. https://www.jpl.nasa.gov/news/news.php?release=2014-321

[32] Chien, P. (200) Endeavour Maps the World in Three Dimensions. Geoworld, 37, 
32-38.

[33] Rabus, B., Eineder, M., Roth, A. and Bamler, R. (2003) The Shuttle Radar Topography Mission: A New Class of Digital Elevation Models Acquired by Spaceborne Radar. ISPRS Journal of Photogrammetry \& Remote Sensing, 57, 241-262. https://doi.org/10.1016/S0924-2716(02)00124-7

[34] ASTER Global Digital Elevation Model (GDEM) Validation Team (2019) Release of ASTER GDEM Version 2. https://ssl.jspacesystems.or.jp/ersdac/GDEM/E/4.html

[35] Eletrosul Centrais Elétricas S.A. (2011) UHE Passo São João-Informações Sobre o Programa Básico Ambiental. Relatório Técnico, Florianópolis.

[36] Eletrosul Centrais Elétricas S.A. (2019) Informações sobre ações socioambientais da UHE São Domingos.

http://www.eletrosul.gov.br/sustentabilidade/acoes-socioambientais-nas-usinas/pro gramas-socioambientais-da-uhe-sao-domingos 